\title{
Detangling catalyst modification reactions from the oxygen evolution reaction by online mass spectrometry
}

Abril, P.; Rio, M.P. del; Tejel, C.; Verhoeven, T.W.G.M.; Niemantsverdriet, J.W.; Ham, C.J.M.; ... ; Hetterscheid, D.G.H.

\section{Citation}

Abril, P., Rio, M. P. del, Tejel, C., Verhoeven, T. W. G. M., Niemantsverdriet, J. W., Ham, C. J. M., ... Hetterscheid, D. G. H. (2016). Detangling catalyst modification reactions from the oxygen evolution reaction by online mass spectrometry. Acs Catalysis, 6(11), 7872-7875.

doi:10.1021/acscatal.6b02800

Version: $\quad$ Publisher's Version

License: $\quad$ Licensed under Article 25fa Copyright Act/Law (Amendment Taverne)

Downloaded from: https://hdl.handle.net/1887/3199902

Note: To cite this publication please use the final published version (if applicable). 


\title{
Detangling Catalyst Modification Reactions from the Oxygen Evolution Reaction by Online Mass Spectrometry
}

\author{
Paula Abril, ${ }^{\dagger}$ M. Pilar del Río, ${ }^{\dagger}{\text { Cristina Tejel, }{ }^{*} \dagger}^{\dagger}$ Tiny W. G. M. Verhoeven, ${ }^{*}$
}

J. W. Hans Niemantsverdriet, ${ }^{\S}$ Cornelis J. M. Van der Ham," Konstantin G. Kottrup," and Dennis G. H. Hetterscheid*,

${ }^{\dagger}$ Departamento de Química Inorgánica, Instituto de Síntesis Química y Catálisis Homogénea-ISQCH, CSIC-Universidad de Zaragoza, Pedro Cerbuna 12, 50009 Zaragoza, Spain

${ }^{\ddagger}$ Department of Chemical Engineering and Chemistry, Eindhoven University of Technology, P.O. Box 513, 5600 MB Eindhoven, The Netherlands

${ }^{\S}$ SynCat@DIFFER, Syngaschem BV, P.O. Box 6336, 5600 HH Eindhoven, The Netherlands

"Leiden Institute of Chemistry, Leiden University, Einsteinweg 55, 2333 CC Leiden, The Netherlands

\section{Supporting Information}

ABSTRACT: Here we showcase the synthesis and catalytic response of the anionic iridium(III) complex $\left[\mathrm{IrCl}_{3}(\mathrm{pic})(\mathrm{MeOH})\right]^{-}\left([1]^{-}\right.$, pic $=$picolinate $)$toward the evolution of oxygen. Online electrochemical mass spectrometry experiments illustrate that an initial burst of $\mathrm{CO}_{2}$ due to catalyst degradation is expelled before the oxygen evolution reaction commences. Electrochemical features and XPS analysis illustrate the presence of iridium oxide, which is the true active species.

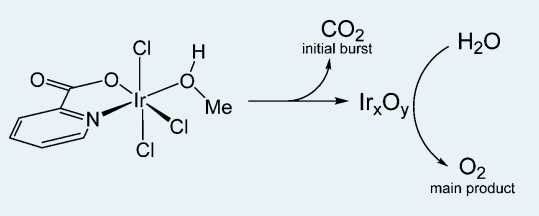

KEYWORDS: oxygen evolution reaction

Since the discovery by Bernhard and co-workers that $\checkmark$ cyclometalated iridium aquo complexes are active in the water oxidation reaction, ${ }^{1}$ various iridium complexes have been studied in order to convert renewable energy (electricity) into chemical fuels. $^{2-15}$ In particular, complexes bearing pentamethylcyclopentadienyl ( $\mathrm{Cp}^{*}$ ) ligands have received much attention, as such catalysts have turned out to be very active. $^{6-15}$ However, the fate of the $\mathrm{Cp} *$ ligand is a topic of debate and the ligand is believed to be heavily modified under the oxidative conditions applied ${ }^{16}$ and eventually lost to generate the true active species. ${ }^{17}$ When in addition to $\mathrm{Cp}^{*}$ a robust ligand is coordinated to iridium, these catalytic species are predominantly considered to be of a molecular nature. ${ }^{17-20}$ In the absence of such ancillary ligands an iridium oxide layer is typically formed on the electrode interface, ${ }^{21-23}$ which is known to be a very potent heterogeneous catalyst for the water oxidation reaction. $^{24,25}$

Ligands based on picolinic acid frameworks are considered to be much more robust and have been used to generate very active molecular ruthenium catalysts by the Sun and Llobet groups using 2,2'-bipyridine-6,6'-dicarboxylate and $2,2^{\prime}: 6^{\prime}, 2^{\prime \prime}$ terpyridine-6,6" -dicarboxylate, respectively. ${ }^{26,27}$ Considering that the picolinate complex $\left[\operatorname{Ir}\left(\mathrm{Cp}^{*}\right)(\mathrm{pic})\left(\mathrm{NO}_{3}\right)\right]$ is the most active molecular iridium catalyst to date ${ }^{9}$ and is believed to lose the $\mathrm{Cp}^{*}$ ligand at some point, we anticipated that $\left[\mathrm{Ir}^{\mathrm{III}} \mathrm{Cl}_{3}\right.$ (pic)$(\mathrm{MeOH})]^{-}\left([\mathbf{1}]^{-}\right.$; Scheme 1$)$ would be an interesting entry into catalysis as well. Catalytic activity is indeed observed in the presence of $[\mathbf{1}]^{-}$, albeit with a substantial lag time.

In order to develop new and better catalysts to split water, it is essential to understand how water oxidation catalysts are
Scheme 1. Synthesis of (HpicMe)[1] and Molecular Structure (ORTEP at the $50 \%$ Level) of the Compound

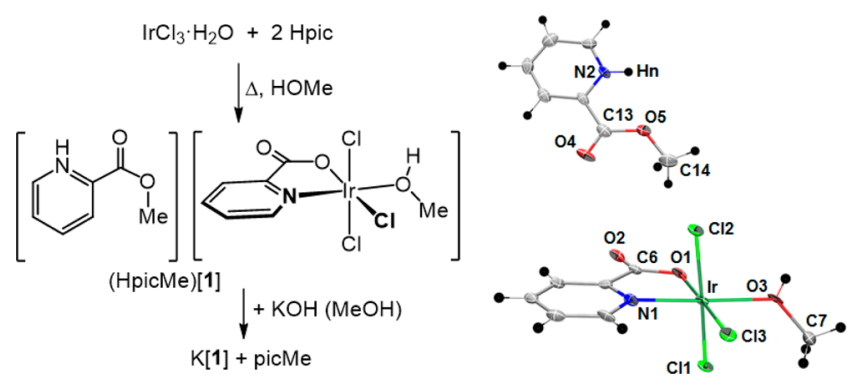

activated. In this contribution we showcase that online MS in combination with electrochemical techniques is a very valuable tool to distinguish between the evolution of dioxygen and catalyst modification reactions and thereby allows us to obtain crucial information regarding activation of $[1]^{-}$. Using these techniques, we demonstrate that $[\mathbf{1}]^{-}$is not a catalyst for the water oxidation reaction itself and that catalytic activity only takes place after decomposition of the organic ligands and formation of iridium oxide at the electrode interface.

The compound (HpicMe) $\left[\mathrm{IrCl}_{3}(\right.$ pic $\left.)(\mathrm{MeOH})\right]((\mathrm{HpicMe})-$ [1]) results straightforwardly from the reaction of $\mathrm{IrCl}_{3} \cdot \mathrm{H}_{2} \mathrm{O}$ with 2 equiv of picolinic acid (Hpic) in refluxing $\mathrm{MeOH}$ (Scheme 1). Interestingly, the cation in the isolated salt comes

Received: September 30, 2016

Published: October 6, 2016 
from a simultaneous esterification reaction of Hpic. Cation exchange in (HpicMe)[1] by reaction with $\mathrm{KOH}$ produced $\mathrm{K}[\mathbf{1}]$ along with the methylpicolinate ester (picMe, ${ }^{1} \mathrm{H}$ NMR evidence). Full characterization and spectroscopic data of the isolated (HpicMe) $[1]$ and $\mathrm{K}[\mathbf{1}]$ complexes are provided in the Supporting Information.

The complex (HpicMe)[1] was drop-casted onto a pyrolytic graphite (PG) working electrode and evaluated for water oxidation catalysis at $\mathrm{pH}$ 1. A close inspection of a series of consecutive CVs indicated an oxidative modification of the catalytic material. Two irreversible oxidation waves observed in the first scan were not reproduced in the following series of cyclic voltammetry scans (Figure 1, left). Similar results were

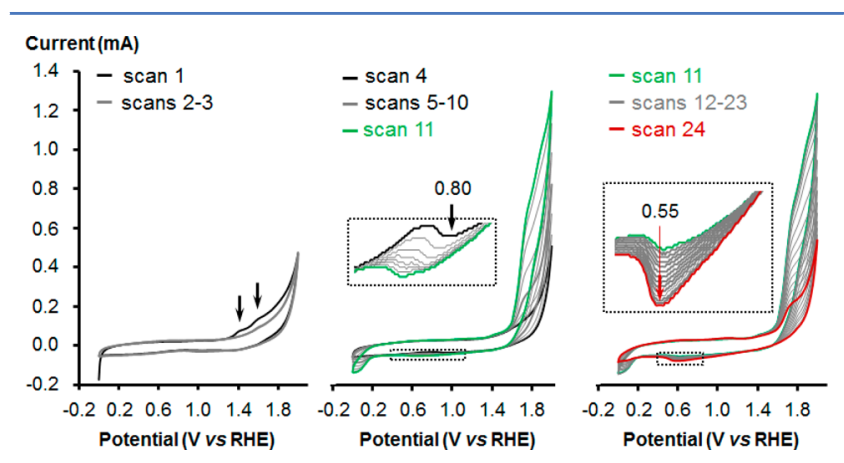

Figure 1. Voltammograms for water oxidation of (HpicMe) $[1](5 \mu \mathrm{L}$ of a $8 \mathrm{mM}$ solution) drop-casted onto the surface of a PG electrode in acid electrolyte solution $0.1 \mathrm{M} \mathrm{HClO}_{4}$ : scans $1-3$ (activation, left); scans 4-11 (catalytic activity, middle); scans 11-24 (deactivation, right). The scan rate was $50 \mathrm{mV} \mathrm{s}^{-1}$. The intensity scale is the same in both insets.

obtained in the case of $\mathrm{K}[\mathbf{1}]$ (Figure S8 in the Supporting Information), in line with decomposition of $[1]^{-}$. Moreover, after 3 scans with a potential window from 0 to $2 \mathrm{~V}$ (vs RHE) a further change in the deposited material must occur, since a great water oxidation activity accompanied by the formation of oxygen bubbles on the surface of the PG electrode was observed (Figure 1, middle). The catalytic wave starting at 1.6 $\mathrm{V}$ was found to be accompanied by a reduction wave with an onset at $0.1 \mathrm{~V}$ that we assigned to the oxygen reduction reaction. After 11 scans $(0-2 \mathrm{~V})$ the catalytic activity considerably decreases (Figure 1, right). Additionally, a wellresolved second reduction wave observed at $0.80 \mathrm{~V}$ (scan 4) shifts to lower potentials upon repetitive scanning and eventually stabilizes at $0.55 \mathrm{~V}$ (scan 24) (inset Figure 1, middle and right). These observations illustrate that the catalytic species is gradually changing during potential cycling. Such a gradual change in electronic properties does point to a heterogeneous species ${ }^{28}$ rather than a molecular catalyst that undergoes electronic modifications. For the latter system one would expect to find different redox waves and not a shifting redox couple.

The rates for the induction time were found to be strongly dependent on the applied potential, as nicely shown in the chronoamperograms depicted in Figure 2. The catalysis quickly starts at $2.0 \mathrm{~V}$ (after $32 \mathrm{~s}$ ), while it takes around $82 \mathrm{~s}$ at $1.9 \mathrm{~V}$. A similar trend was observed for the deactivation rates.

The observed current-time profiles are virtually the same for drop-casted (HpicMe)[1] (Figure 2) and (HpicMe) $[1]$ in solution (Supporting Information). In contrast to previous activation processes for molecular iridium complexes ${ }^{18,19}$ no deposition of catalytic material on the electrode was recorded

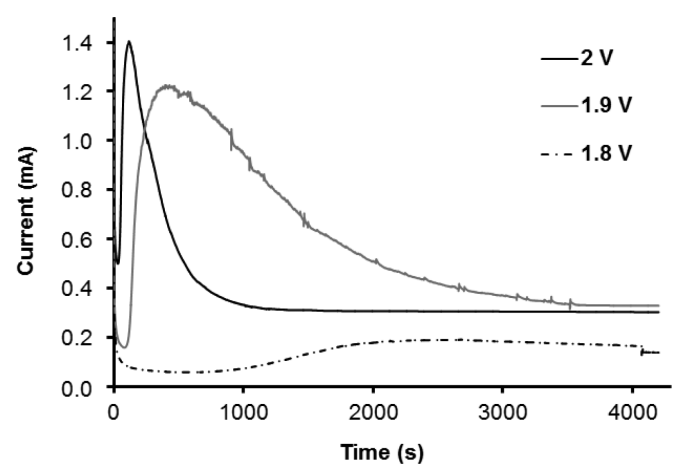

Figure 2. Chronoamperograms of the complex (HpicMe) $[1]$ at 2, 1.9, and $1.8 \mathrm{~V}$ (vs RHE).

by electrochemical quartz crystal microbalance (EQCM) studies. Presumably the catalyst activation time is too long when $[1]^{-}$is present in solution to deposit relatively large amounts of iridium oxide onto the electrode. In order to verify which gaseous products are formed as a function of applied potential and time, we rely on online electrochemical mass spectrometry (OLEMS), which is a qualitative method to follow the relative formation of gaseous products in time and in correlation to the current profile. ${ }^{29}$ In a previous study we showed in the case of iron cyclam complexes that dioxygen is evolved immediately, suggesting that the true active species at least is formed instantaneously and presumably is the molecular iron complex itself. ${ }^{30}$ Amperometry experiments in the case of (HpicMe)[1] show a response of the $\mathrm{m} / z 32$ trace, corresponding to the molecular mass of $\mathrm{O}_{2}$, that has a considerable lag time. The spikes that can be observed in the mass trace as a function of time are due to gas bubble formation (Figure 3). The mass response is in perfect agreement with the

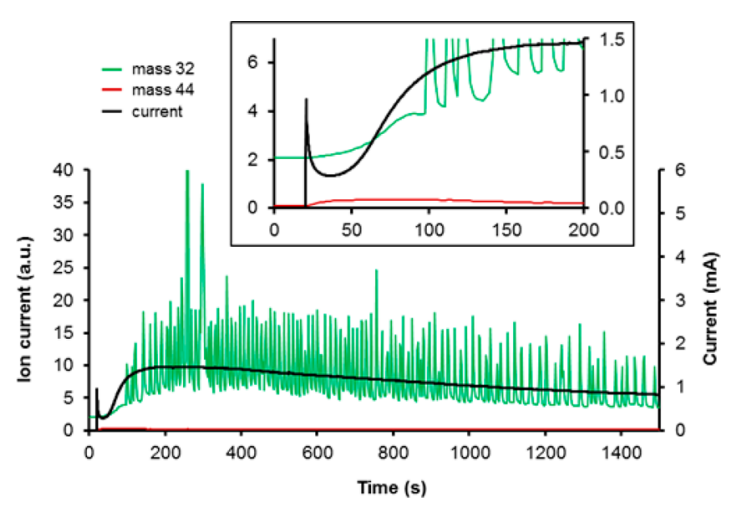

Figure 3. Chronoamperometry at $1.9 \mathrm{~V}$ versus RHE in combination with OLEMS in the presence of $(\mathrm{HpicMe})[1]$ in $0.1 \mathrm{M} \mathrm{HClO}_{4}$. Depicted are the current (black), the $m / z 32$ trace belonging to $\mathrm{O}_{2}$ (green), and the $m / z 44$ trace belonging to $\mathrm{CO}_{2}$ (red).

current profile during the amperometry experiment and suggests that the water oxidation reaction is the predominant oxidative process overall.

Since carbon dioxide is a potential degradation product of picolinic acid, the $m / z 44$ trace was also monitored. From the $\mathrm{CO}_{2}$ trace one can conclude that the initial oxidation processes result in massive destruction of the organic moieties. In this discussion it is important to note that also the PG electrode produces $\mathrm{CO}_{2}$ under oxidative conditions, yet at $1.9 \mathrm{~V}$ versus RHE these amounts are negligible in comparison to the $\mathrm{CO}_{2}$ 
trace in Figure 3 (see the Supporting Information). Apparently, the iridium complex changes into a new species that in turn is able to oxidize water. Given the initial oxidative currents in the cyclic voltammetry (Figure 1), it appears that oxidation of the organic moieties occurs instantaneously in the very first cyclic voltammetry scan.

Identification of the species at different stages of the catalyst lifetime was carried out by means of XPS measurements. Although the carbon and oxygen signals are not very informative (Supporting Information), the iridium and nitrogen signals are enlightening. Figure S5 (bottom left) in the Supporting Information shows the XPS data for the nitrogen in which the signal at a BE of 400.5 disappears with the reaction progress. Figure S5 (bottom right) shows a BE of 61.4 when no potential is applied, which is in line with a +III oxidation state of iridium. ${ }^{19}$ After short-term electrolysis the iridium signal shifts to a BE of 62.0 , which lies below that of molecular iridium(IV) species $(62.4-62.2)^{17,19,20}$ and is in the general area where one expects to find iridium(III) oxide $(\sim 61.8) .{ }^{19,31,32}$

In contrast to the cyclic voltammograms at $\mathrm{pH} 1$, no significant catalytic activity was observed at $\mathrm{pH} 12$ and $\mathrm{pH} 6$ (Figures S6 and S7 in the Supporting Information). Since iridium oxide is known to be active under these conditions as well, ${ }^{25}$ the apparent $\mathrm{pH}$ effect must be linked to the catalyst modification reactions taking place under oxidative conditions. In this discussion, it is important to note that $[1]^{-}$is stable in aqueous solutions of $\mathrm{pH} 1$ (Figure $\mathrm{S} 4$ in the Supporting Information). The observed catalyst activation is therefore most likely not due to a ligand hydrolysis pathway, and the $\mathrm{pH}$ effect is probably related to an oxidation process in the catalyst activation phase that is not coupled to a proton transfer reaction, in contrast to the water oxidation reaction and the RHE reference scale. The oxidative catalyst activation reaction therefore would occur at much higher potentials on the RHE reference scale at neutral and alkaline $\mathrm{pH}$. Hence, we did not observe activity under these latter conditions. In line with these results, samples that were activated at acidic $\mathrm{pH}$ first do retain catalytic activity when they were moved to an alkaline solution yet deactivate very quickly, in line with literature results (Figure S9 in the Supporting Information). ${ }^{25}$

Whereas the pyridine- and bipyridinedicarboxylate ligands turned out to be very robust in ruthenium-mediated water oxidation catalysis, in the coordination sphere of $[1]^{-}$picolinate is readily lost under the oxidative conditions employed. This once more proves that the ligand stability in molecular water oxidation catalysis is highly dependent on the reaction conditions applied. In contrast to formation of iridium oxide from $\left[\operatorname{Ir}\left(\mathrm{Cp}^{*}\right)\left(\mathrm{OH}_{2}\right)_{3}\right]^{2+}$ that instantaneously produces a blue layer of iridium oxide, ${ }^{22}$ there appears to be a substantial lag time between ligand oxidation and evolution of dioxygen. Apparently, active iridium oxide is not formed instantaneously in the case of $[\mathbf{1}]^{-}$, even though the only signs of ligand degradation are observed in the very first cyclic voltammetry scan, starting barely above the equilibrium potential of water. This may be the result of slow dissociation of partly oxidized ligand(s) or chloride, resulting in a delayed catalytic activity.

It is remarkable that no significant activity was observed for $[1]^{-}$, as $\left[\operatorname{Ir}\left(\mathrm{Cp}^{*}\right)(\mathrm{pic})\left(\mathrm{NO}_{3}\right)\right]$ was reported to be one of the most potent iridium water oxidation catalysts reported thus far. ${ }^{9}$ Clearly both species do not result in the same active species. This may suggest that the $\mathrm{Cp}^{*}$ ligand is still somehow involved in the chemistry of $\left[\operatorname{Ir}\left(\mathrm{Cp}^{*}\right)(\mathrm{pic})\left(\mathrm{NO}_{3}\right)\right]$ under oxidative conditions but could also point to some involvement of chloride in the chemistry of $[1]^{-}$.

The reduction signal observed around $0.7 \mathrm{~V}$ vs RHE upon prolonged potential cycling is indicative of formation of iridium oxide $^{28}$ although the oxidation wave is hardly visible due to the large double layer of the graphite. Since $[\mathbf{1}]^{-}$is drop-casted onto the electrode, the amount of iridium on the electrode interface should be more or less constant or slightly decreasing at best. The persistence of the redox couple at $\sim 0.6 \mathrm{~V}$ versus RHE in cyclic voltammetry suggests that desorption is not very significant.

Whether $\mathrm{O}_{2}$ is observed immediately or is preceded by ligand degradation is an important research question to answer in order to understand the water oxidation reaction mediated by molecular systems, yet this has rarely been addressed in an electrochemical context. Online MS offers an important tool to detangle these oxidative decomposition reactions from true water oxidation catalysis. In the present case we showed that ligand degradation of $[\mathbf{1}]^{-}$occurs prior to evolution of dioxygen and that iridium oxide is the true active species.

\section{ASSOCIATED CONTENT}

\section{Supporting Information}

The Supporting Information is available free of charge on the ACS Publications website at DOI: 10.1021/acscatal.6b02800.

Selected NMR data and electrochemical and XPS measurements (PDF)

Crystallographic data (CIF)

\section{AUTHOR INFORMATION}

\section{Corresponding Authors}

*E-mail for C.T.: ctejel@unizar.es.

*E-mail for D.G.H.H.: d.g.h.hetterscheid@chem.leidenuniv.nl.

\section{Notes}

The authors declare no competing financial interest.

\section{ACKNOWLEDGMENTS}

Generous financial support from the MINECO/FEDER (CTQ2014-53033-P; C.T.) and Gobierno de Aragón/FSE (GA/FSE, Inorganic Molecular Architecture Group, E70; C.T.) is gratefully acknowledged. P.A. and M.P.d.R. thank the MINECO/FEDER for a fellowship and a JdC contract, respectively.

\section{REFERENCES}

(1) McDaniel, N. D.; Coughlin, F. J.; Tinker, L. L.; Bernhard, S. J. Am. Chem. Soc. 2008, 130, 210-217.

(2) Hetterscheid, D. G. H.; Reek, J. N. H. Angew. Chem., Int. Ed. 2012, 51, 9740-9747.

(3) Blakemore, J. D.; Crabtree, R. H.; Brudvig, G. W. Chem. Rev. 2015, 115, 12974-13005.

(4) Thomsen, J. M.; Huang, D. L.; Crabtree, R. H.; Brudvig, G. W. Dalton Trans. 2015, 44, 12452-12472.

(5) Dzik, W. I.; Calvo, S. E.; Reek, J. N. H.; Lutz, M.; Ciriano, M. A.; Tejel, C.; Hetterscheid, D. G. H.; de Bruin, B. Organometallics 2011, 30, 372-374.

(6) Woods, J. A.; Lalrempuia, R.; Petronilho, A.; McDaniel, N. D.; Muller-Bunz, H.; Albrecht, M.; Bernhard, S. Energy Environ. Sci. 2014, 7, 2316-2328.

(7) Petronilho, A.; Woods, J. A.; Mueller-Bunz, H.; Bernhard, S.; Albrecht, M. Chem. - Eur. J. 2014, 20, 15775-15784. 
(8) Diaz-Morales, O.; Hersbach, T. J. P.; Hetterscheid, D. G. H.; Reek, J. N. H.; Koper, M. T. M. J. Am. Chem. Soc. 2014, 136, 1043210439.

(9) Bucci, A.; Savini, A.; Rocchigiani, L.; Zuccaccia, C.; Rizzato, S.; Albinati, A.; Llobet, A.; Macchioni, A. Organometallics 2012, 31, 80718074.

(10) Savini, A.; Bellachioma, G.; Ciancaleoni, G.; Zuccaccia, C.; Zuccaccia, D.; Macchioni, A. Chem. Commun. 2010, 46, 9218-9219.

(11) Blakemore, J. D.; Schley, N. D.; Balcells, D.; Hull, J. F.; Olack, G. W.; Incarvito, C. D.; Eisenstein, O.; Brudvig, G. W.; Crabtree, R. H. J. Am. Chem. Soc. 2010, 132, 16017-16029.

(12) Navarro, M.; Li, M.; Müller-Bunz, H.; Bernhard, S.; Albrecht, M. Chem. - Eur. J. 2016, 22, 6740-6745.

(13) Hull, J. F.; Balcells, D.; Blakemore, J. D.; Incarvito, C. D.; Eisenstein, O.; Brudvig, G. W.; Crabtree, R. H. J. Am. Chem. Soc. 2009, $131,8730-8731$.

(14) Hetterscheid, D. G. H.; Reek, J. N. H. Chem. Commun. 2011, 47, 2712-2714.

(15) Li, M.; Takada, K.; Goldsmith, J. I.; Bernhard, S. Inorg. Chem. 2016, 55, 518-526.

(16) Savini, A.; Belanzoni, P.; Bellachioma, G.; Zuccaccia, C.; Zuccaccia, D.; Macchioni, A. Green Chem. 2011, 13, 3360-3374.

(17) Hintermair, U.; Sheehan, S. W.; Parent, A. R.; Ess, D. H.; Richens, D. T.; Vaccaro, P. H.; Brudvig, G. W.; Crabtree, R. H. J. Am. Chem. Soc. 2013, 135, 10837-10851.

(18) Schley, N. D.; Blakemore, J. D.; Subbaiyan, N. K.; Incarvito, C. D.; D'Souza, F.; Crabtree, R. H.; Brudvig, G. W. J. Am. Chem. Soc. 2011, 133, 10473-10481.

(19) Hetterscheid, D. G. H.; Van der Ham, C. J. M.; Diaz-Morales, O.; Verhoeven, M. W. G. M.; Longo, A.; Banerjee, D.; Niemantsverdriet, J. W.; Reek, J. N. H.; Feiters, M. C. Phys. Chem. Chem. Phys. 2016, 18, 10931-10940.

(20) Sheehan, S. W.; Thomsen, J. M.; Hintermair, U.; Crabtree, R. H.; Brudvig, G. W.; Schmuttenmaer, C. A. Nat. Commun. 2015, 6, 6469.

(21) Blakemore, J. D.; Mara, M. W.; Kushner-Lenhoff, M. N.; Schley, N. D.; Konezny, S. J.; Rivalta, I.; Negre, C. F. A.; Snoeberger, R. C.; Kokhan, O.; Huang, J.; Stickrath, A.; Tran, L. A.; Parr, M. L.; Chen, L. X.; Tiede, D. M.; Batista, V. S.; Crabtree, R. H.; Brudvig, G. W. Inorg. Chem. 2013, 52, 1860-1871.

(22) Blakemore, J. D.; Schley, N. D.; Olack, G. W.; Incarvito, C. D.; Brudvig, G. W.; Crabtree, R. H. Chem. Sci. 2011, 2, 94-98.

(23) Huang, J.; Blakemore, J. D.; Fazi, D.; Kokhan, O.; Schley, N. D.; Crabtree, R. H.; Brudvig, G. W.; Tiede, D. M. Phys. Chem. Chem. Phys. 2014, 16, 1814-1819.

(24) Grotjahn, D. B.; Brown, D. B.; Martin, J. K.; Marelius, D. C.; Abadjian, M. C.; Tran, H. N.; Kalyuzhny, G.; Vecchio, K. S.; Specht, Z. G.; Cortes-Llamas, S. A.; Miranda-Soto, V.; van Niekerk, C.; Moore, C. E.; Rheingold, A. L. J. Am. Chem. Soc. 2011, 133, 19024-19027.

(25) McCrory, C. C. L.; Jung, S. H.; Peters, J. C.; Jaramillo, T. F. J. Am. Chem. Soc. 2013, 135, 16977-16987.

(26) Duan, L. L.; Bozoglian, F.; Mandal, S.; Stewart, B.; Privalov, T.; Llobet, A.; Sun, L. C. Nat. Chem. 2012, 4, 418-423.

(27) Matheu, R.; Ertem, M. Z.; Benet-Buchholz, J.; Coronado, E.; Batista, V. S.; Sala, X.; Llobet, A. J. Am. Chem. Soc. 2015, 137, 1078610795.

(28) Mirbagheri, N.; Chevallier, J.; Kibsgaard, J.; Besenbacher, F.; Ferapontova, E. E. ChemPhysChem 2014, 15, 2844-2850.

(29) Wonders, A. H.; Housmans, T. H. M.; Rosca, V.; Koper, M. T. M. J. Appl. Electrochem. 2006, 36, 1215-1221.

(30) Kottrup, K. G.; Hetterscheid, D. G. H. Chem. Commun. 2016, 52, 2643-2646.

(31) Augustynski, J.; Koudelka, M.; Sanchez, J.; Conway, B. E. J. Electroanal. Chem. Interfacial Electrochem. 1984, 160, 233-246.

(32) Le Vot, S.; Roue, L.; Belanger, D. Electrochim. Acta 2012, 59, 49-56. 